\title{
Design, construction and Performance Evaluation of a Solar Water Pump
}

\author{
*Abdulkadir Baba HASSAN1 and Muhammadu Masin MUHAMMADU² \\ Department of Mechanical Engineering, Federal University of Technology, Minna, Niger State, Nigeria
}

\begin{abstract}
The study evaluated the performance of a solar water pump. The theoretical analysis on the performance evaluation of a solar water pump were made, the pump uses a low boiling point working fluid npentane. A flat plate solar generates vapour and its pressure is adequate to pump water. It shows that the pump can lift 2 litres $\left(0.002 \mathrm{~m}^{3}\right)$ of water per cycle with volumetric flow rate of $0.0003333 \mathrm{~m}^{3} / \mathrm{s}$ for $2 \mathrm{~m}$ discharge head and the pump has an overall efficiency of 53\%. Suggestions and recommendations which have practical implications for flat plate collector and thermodynamics analysis are given.
\end{abstract}

Keywords: Solar, Water Pump, Working Fluid, Flat Plate.

\section{INTRODUCTION}

Energy can be described as that unifying concept of all physical science that associate with any system, a capacity for work either as a result of motion of man in the system (Kinetic energy), the configuration of masses or charges in the system (potential energy) or the presence of photons in the system (radiant energy).

There are many sources and forms of energy. The forms embrace electrical, Mechanical, chemical and atomic energy. These sources of energy can be classified as follows:-

1. Conventional energy source: - This includes firewood, oil, coal and natural gas etc.

2. Renewable energy source: - This includes direct energy from the sun (Solar energy), geothermal, hydro potential, wind, biomass (fuel, wood, agricultural residues etc), ocean waves and tides etc. Those resources although not on a 24-hour continuous availability, can be properly or appropriately harnessed to supplement energy needs.

Solar energy in particular, has such an established pattern that with an appropriate harnessing technology, it is possible to get considerable part of the world's energy needs from it. Solar energy is indeed the energy that is derived directly from the sunshine. The sun is the centre of the solar system with which our life and welfare and that of livestock, agricultural and botanical needs of all depends on for survival. Thus, it is from the sun that foods, materials and all forms of energy are got.

The sun with a surface temperature of about $5762^{\circ} \mathrm{C}$ radiates about $1.353 \mathrm{KW} / \mathrm{m}^{3}$ of solar power on the outside of the earth atmosphere (Bamiro et al, 1982). This is a massive amount of energy that is beamed to the earth for daily use. This $1.353 \mathrm{KW} / \mathrm{m}^{3}$ of solar power falling on the outer atmosphere is reduced to about $1 \mathrm{KW} / \mathrm{m}^{2}$ (Bamiro et al, 1982) because of the following reasons.

Solar radiation passes through the earth surface receives radiation during the day while it progressively cuts off during the night.

The heating of water for domestic uses (bathing, washing, cleaning etc) presently accounts for an appreciable proportion of energy needs. The enormous demand is currently being met primarily through burning of fossil fuels like coal gas, oil etc or use of electricity.

The use of fossil fuel like kerosene and cooking gas is very expensive nowadays in countries that are endowed with natural resources. In the countries that are endowed with it, problems of distribution, lack of technology know-how and excess profiteering by marketers deny must people access to it. In Nigeria for example, the hoarding and diversion of petroleum products to the neighboring countries which resulted in an uneven distribution, coupled with bad roads has further compounded the supply and use of Kerosene and cooking gas by both rural and urban dwellers. As a result of nonavailability of some of these petroleum products, the uses of firewood have been on the increase in demand which causes a lot of deforestation, which has led to desert formation. If the trend is not checked presently, Nigeria will be depleted of wood at the expense of the natural ecological setting.

Solar energy is very pure and inexhaustible. At present the most successful requirements of solar energy seems to be supply of solar water pump, space heating and cooling as well as generating electricity etc. Of these many uses of solar energy, pumping process is one which has been exploited most. It is now being accepted as a practical way of providing domestic pumping water system in Japan, Israel, U.S.A., India, France and some countries in Latin America (Chandra and Oguntuase, 1996).

Nigerian researchers on solar energy and its application would necessarily require two basic sun data. These are extraterrestrial or the extra atmospheric irradiation $\left(\mathrm{H}^{\mathrm{o}}\right)$ and the day light duration $\left(\mathrm{S}^{\mathrm{o}}\right)$. Formulae exist for the evaluation of these parameters. However, the derivations are long and repeated determinations of these quantities are avoided by reference to existing tables and charts at $2^{\circ}$ Latitude intervals for geographical latitude limits of Nigeria (Ezeilo, 1994); for Minna city in particular, we shall refer to data from the meteorological Department of Minna Airport. 
The main objective of this project is to design, construct and to evaluate the performance of a solar water pump with a view to producing pumping operation for water supply for domestic uses, irrigation purposes and livestock uses. Using alternative energy (solar energy). Also, to recommend the possible improvement for further studies/works.

\section{DESIGN CONSIDERATION AND ANALYSIS}

\section{Analysis of Flat Plate Collector Unit}

The analysis is based on the heat transfer and thermodynamic analysis. The flat plate collectors are made of flat plated with good thermal conductivities and having the absorbing surface blackened to improve the rate of absorption. A galvanized metal sheet of thickness $3 \mathrm{~mm}$ was welded to the pipe network. The welding was done in such away that there is an effective thermal contact between the metal sheet and the pipe network. The metal sheet was painted black in the front surface to maximize solar absorption.

The absorber was then enclosed in air tight and weather tight box made of plywood and insulated on its rear sides with foam of $0.0508 \mathrm{~m}$ thickness. The collector was then covered with a transparent glass of $3 \mathrm{~mm}$ thickness and kept at a distance of $3 \mathrm{~cm}$ from the absorber surface (galvanized sheet and pipe network). The glass cover transmits the short wave and high temperature radiation of the sun at the same time acts as a good barrier for long wave and low temperature radiation from the galvanized iron sheet.

In the theoretical analysis, the performance of a solar collector is described by an energy balance that indicates the distribution of incident solar energy into useful energy gain and various losses. The following assumptions are made for simplicity:

1. The performance of the solar water pump flat plate collector is in steady state.

2. The effect of the headers on collector performance is negligible as they form a relatively small portion of the collector surface area and contains disproportional large volume of fluid according to Duffie and Beckman (1980).

3. The air surrounding the collector is at ambient temperature.

4. Tubes, fins, passage or channels, which are integral with or connected to the collector absorber plate, carrying water air or any fluid.

The Separation, Vapour Water and Air Tanks. The upper part of the separation tank houses the generated pentane vapour while the lower part contains the liquid pentane. Vapour from the upper part of separation tank is stored in vapour tank, while the water tank is normally filled with water and incorporates a cooling coil. The air tank contains air under atmospheric pressure, and the surface water source has a rubber tube inside.

\section{Orientation of the Collector Unit}

According to Olusoji (1983), he suggested that for the best all round performance of solar water pump, the collector should be inclined at about $10^{\circ}$ plus of the geographical latitude. In this case, the geographical latitude of Minna is $9.62^{\circ} \mathrm{N}$ and the collector unit is inclined at $19.62^{\circ}$ to the horizontal.

\section{Total Radiation on the Tilted Surface of the Collector Unit}

Flat plate collector absorbs both bean and diffuse radiation. This is one of the advantages it has over other collectors.

According to Duffie and Beckman (1980), using approximate equation of cooper, the declination, $\varphi$ i.e. angular position of the sun at solar noon with respect to the plane of equator is:-

$$
\Psi=23.4 \sin \left[\left(360 \frac{(284+N)]}{365}\right.\right.
$$

The amount of the diffuse component of solar collector is given by Mc Daniel (1978), as

$$
\frac{H_{D}}{H_{S}}=\frac{1}{2}(1+\cos S)
$$

And

$\mathrm{H}_{\mathrm{s}} \quad=\mathrm{H}_{\mathrm{B}}+\mathrm{H}_{\mathrm{D}}$

The total radiation $\mathrm{H}$ on the tilted surface is

$$
\mathrm{H}=\mathrm{H}_{\mathrm{B}} \mathrm{R}_{\mathrm{B}}+\mathrm{H}_{\mathrm{D}}
$$

\section{The Transmitance-Absorptance Product of the Cover and Absorber Plate System}

The Transmittance - Absorptance product of the cover and the absorber plate system is given by Diffie and Beckman (1980), as:-

$$
\tau \alpha=\frac{\tau \alpha}{1(1-\alpha) \rho d}
$$

$$
\text { Where }
$$

$\rho_{d}=0.16$ for 1 glass

$\rho_{d}=0.24$ for 2 glass

$\rho_{d}=0.29$ for 3 glass

\section{The useful Energy Gain of the Collector as a} Function of the Inlet Fluid Temperature.

The useful energy gain of the collector can be calculated as a function of the inlet fluid temperature according to Duffie and Beckman (1980), thus 


$$
Q_{u}=A_{c} F_{R}\left\lfloor H_{\tau \alpha}-U_{L}\left(T_{f i}-T_{a}\right)\right\rfloor
$$

However, it must be remembered that losses based on the inlet fluid temperature are too small since losses occur all along the collector and the fluid has an ever-increasing temperature in the flow direction. The effect of the multiplier $F_{R}$ is to reduce the calculated useful energy gain from what it would have been, had the whole collector been at the inlet fluid temperature.

\section{The Collector Efficient}

The hourly and daily efficiencies of the collector are directly related to the collector performance. These efficiencies which indicate the rate at which incident solar energy is being converted into useful thermal energy by the collector unit, are obtained as follows:-

$$
\eta_{H}=\frac{Q_{U} / A_{C}}{H}
$$

Where $\eta_{H}$ is the hourly efficiency

$\eta_{D}=\frac{\Sigma Q_{u} / A_{C}}{\Sigma H}$

\section{Power and Efficiency of Pump}

Power is the energy per unit time, and mechanical energy is needed to lift a certain amount of water from a depth and discharge it to an elevation.

$\mathrm{P}=\mathrm{E} / \mathrm{t}$

If $\mathrm{Q}^{\circ}$ is the volumetric flow rate of water the mechanical power required for pumping is given by

$p=\frac{Q^{0} C H_{1}+H_{2}+L}{\eta}$

$P=\ell g H Q^{2}$

Where: $\mathrm{P}$ is the power, $\mathrm{L}$ is the fractional losses in the piping system from the well to the storage tank, $\mathrm{S}$ is the pump mechanical efficiency, $\mathrm{H} 1+\mathrm{H} 2=\mathrm{h}$-the number of cycles per day, $\mathrm{N}$ is the number of times the pump can lift water.

Therefore the hydraulic worskdone by pump/cycle is:

$W_{c}=V \ell_{W} g h$

Where : h refers to the discharge head, Pw is density of water and $\mathrm{g}$ is the acceleration due to gravity.

The overall efficiency $\mathrm{S}$ of the pump is given by
Where: $\mathrm{H}_{\mathrm{tot}}$ is the total solar radiation incident on the collector during the operation of the pump.

\section{Operational mode of the pump and maintenance}

Liquid n-pentane set in motion by thermosyhon action is heated in the flat plate collector. Saturated pentane vapor, separating in tank $\mathrm{S}$ is stored in tank $\mathrm{V}$. Thereafter, the vapor from tank $\mathrm{V}$ while entering tank W displaces water to tank $A$ and subsequently, the compressed air is used to inflate the tube located inside the water source. The tube acts like bellows by exerting pressure on water and water is pushed through flexible hose to the overhead tank $\mathrm{T}$ due to displacement.

At the end of pumping operation, water in overhead tank is pass through the cooling coil in tank W to accelerate the condensation of vapor. This restores the pressure in tank W (but not in the collector) to its original value. Thus one cycle is performed.

In order to keep the system in continuous or function the following maintenance procedure should be carried out.

1) The glass cover should be cleaned regularly from dust , moisture and other impurities which tend to cover it and checked for breakage and should be replaced with a new one if there is any

2) The connecting pipe joints should be checked for leakages and sealed if there is any and

3) The collector system should not be exposed to rainfalls as it tends to damage the collector.

\section{Testing}

\section{Solar collector performance tests}

The solar water pump with flat plate collector was stationed outside for effective tracking of the sun. Mercury in -glass thermometers were mounted at the following points

1. The inlet pipe of the collector in order to measure the temperature of the liquid n-pentane before entering the collector.

2. The outlet pipe of the collector. Solarimeter was used to measure the solar radiation intensity and value obtained are shown table 5.1 the tests were carried out on the $26^{\text {th }}$ and $27^{\text {th }}$ October, 2006. eh inlet and outlet collector temperature readings as well as tehsolar radiation readings were recorded on an hourly basis. The collector hourly and daily efficiencies as well as the useful heat gain by the collector were determined using equations 7,8 and 9 respectively and the collector hourly performance coefficient $\left(\mathrm{T}_{\mathrm{fi}}-\mathrm{T}_{\mathrm{fo}}\right) / \mathrm{H}$ are shown in table 1 .
$\eta=\frac{N W_{L}}{H_{t o t}}$ 
IOSR Journal of Engineering

Apr. 2012, Vol. 2(4) pp: 711-718

Table 1: $26^{\text {th }}$ October 2006 test readings and technical performance evaluation of the collector unit

\begin{tabular}{|c|c|c|c|c|c|c|c|}
\hline $\begin{array}{l}\text { Period } \\
\text { Hour }\end{array}$ & $\begin{array}{l}\text { Ambient } \\
\text { temperature } \\
\mathrm{Ta}\left({ }^{0} \mathrm{C}\right)\end{array}$ & $\begin{array}{l}\text { Collector } \\
\text { fluid outlet } \\
\text { temp. } \\
\text { Tfo( }\left({ }^{0} \mathrm{C}\right)\end{array}$ & $\begin{array}{l}\text { Collector } \\
\text { fluid outlet } \\
\text { temp. } \\
\text { Tfo }\left({ }^{\circ} \mathrm{C}\right)\end{array}$ & $\begin{array}{l}\text { Solar } \\
\text { radia } \\
\text { intensity } \\
\text { on the } \\
\text { collector } \\
\text { tilted } \\
\text { surface } \\
(w / m 2)\end{array}$ & $\begin{array}{l}\text { Useful heat } \\
\text { gain by the } \\
\text { collector, } \\
\text { Qu(w/m2) }\end{array}$ & $\begin{array}{l}\begin{array}{l}\text { Collector } \\
\text { hourly } \\
\text { efficiency }\end{array} \\
\eta_{H}=\frac{Q_{H}}{H}\end{array}$ & $\begin{array}{c}\begin{array}{c}\text { Performance } \\
\text { coefficient } \\
\left(T_{f i}-T_{a}\right)\end{array} \\
H \\
\left({ }^{0} \mathrm{Cm}^{2} / W\right.\end{array}$ \\
\hline $8-9$ & 31 & 37 & 40 & 285.61 & 133.10 & 0.46 & 0.03 \\
\hline $9-10$ & 34 & 41 & 45 & 304.11 & 148.15 & 0.48 & 0.02 \\
\hline $10-11$ & 34 & 47 & 56 & 652.83 & 319.20 & 0.49 & 0.02 \\
\hline $11-12$ & 35 & 54 & 57 & 855.73 & 415.90 & 0.49 & 0.02 \\
\hline $12-1$ & 36 & 63 & 64 & 868.10 & 376.13 & 0.43 & 0.02 \\
\hline $1-2$ & 36 & 67 & 69 & 871.08 & 370.93 & 0.42 & 0.03 \\
\hline $2-3$ & 38 & 70 & 72 & 873.80 & 360.61 & 0.41 & 0.04 \\
\hline $3-4$ & 36 & 70 & 77 & 859.66 & 341.90 & 0.39 & 0.04 \\
\hline $4-5$ & 34 & 66 & 72 & 641.97 & 215.35 & 0.34 & 0.05 \\
\hline $5-6$ & 33 & 64 & 67 & 282.62 & 13.36 & 0.33 & 0.11 \\
\hline
\end{tabular}

$$
\begin{aligned}
& \eta_{D}=\frac{\sum Q_{u}}{\sum H} \\
& \eta_{D}=\frac{2812.63}{6495.51} \\
& =0.43 \%
\end{aligned}
$$

Table 2: $27^{\mathrm{TH}}$ October 2006 test readings and technical performance evaluation of the collector unit

\begin{tabular}{|c|c|c|c|c|c|c|c|}
\hline $\begin{array}{c}\text { Period } \\
\text { Hour }\end{array}$ & $\begin{array}{c}\text { Ambient } \\
\text { temperature } \\
\mathbf{T a}\left({ }^{\circ} \mathbf{C}\right)\end{array}$ & $\begin{array}{c}\text { Collector fluid } \\
\text { outlet temp. } \\
\left.\text { Tfo( }{ }^{(} \mathbf{C}\right)\end{array}$ & $\begin{array}{c}\text { Collector fluid } \\
\text { outlet temp. Tfo }\left({ }^{\circ} \mathbf{C}\right)\end{array}$ & $\begin{array}{c}\text { Solar radia } \\
\text { intensity on } \\
\text { the collector } \\
\text { tilted surface } \\
(\mathbf{w} / \mathbf{m} 2)\end{array}$ & $\begin{array}{c}\text { Useful heat gain } \\
\text { by the collector, } \\
\mathbf{Q u}(\mathbf{w} / \mathbf{m} 2)\end{array}$ & $\begin{array}{c}\text { Collector } \\
\text { hourly } \\
\text { efficiency } \\
\eta_{H}=\frac{Q_{H}}{H}\end{array}$ & $\begin{array}{c}\text { Performance } \\
\text { coefficient } \\
\left(T_{f i}-T_{a}\right)\end{array}$ \\
\hline $8-9$ & 30 & 37 & 39 & 286.73 & 135.10 & 0.47 & 0.02 \\
\hline $9-10$ & 32 & 39 & 44 & 310.11 & 149.11 & 0.48 & 0.03 \\
\hline $10-11$ & 34 & 46 & 54 & 652.44 & 320.52 & 0.49 & 0.02 \\
\hline $11-12$ & 35 & 52 & 61 & 855.82 & 415.89 & 0.49 & 0.02 \\
\hline $12-1$ & 36 & 60 & 67 & 869.12 & 366.14 & 0.42 & 0.03 \\
\hline $1-2$ & 36 & 65 & 70 & 872.05 & 366.15 & 0.42 & 0.03 \\
\hline $2-3$ & 37 & 68 & 72 & 873.02 & 359.31 & 0.41 & 0.03 \\
\hline $3-4$ & 35 & 67 & 70 & 858.77 & 340.71 & 0.40 & 0.04 \\
\hline $4-5$ & 34 & 65 & 69 & 642.88 & 214.24 & 0.33 & 0.04 \\
\hline $5-6$ & 32 & 63 & 66 & 292.63 & 13.11 & 0.04 & 0.09 \\
\hline
\end{tabular}

The daily efficiency

$$
\eta_{D}=\frac{\sum Q_{u}}{\Sigma H}
$$


IOSR Journal of Engineering

Apr. 2012, Vol. 2(4) pp: 711-718

$\eta_{D}=\frac{2680.28}{6513.57}$

$=0.41$

The experimental collector hourly efficiency $\eta_{H}$ was plotted as a function of the performance coefficient, $\left(\mathrm{T}_{\mathrm{fi}}{ }^{\mathrm{Ta}}\right)/ \textrm{H}$ to obtain the experimental thermal efficiency curve of the collector for the tests carried out on $26^{\text {th }}$

and $27^{\text {th }}$ of October, 2006 as shown in figure 1., each sign or symbol in figure 1 is used to represents the data as shown below.

Fig. 1: Experimental Thermal efficiency curve of the collector for the test

$\eta_{\mathrm{H}}$

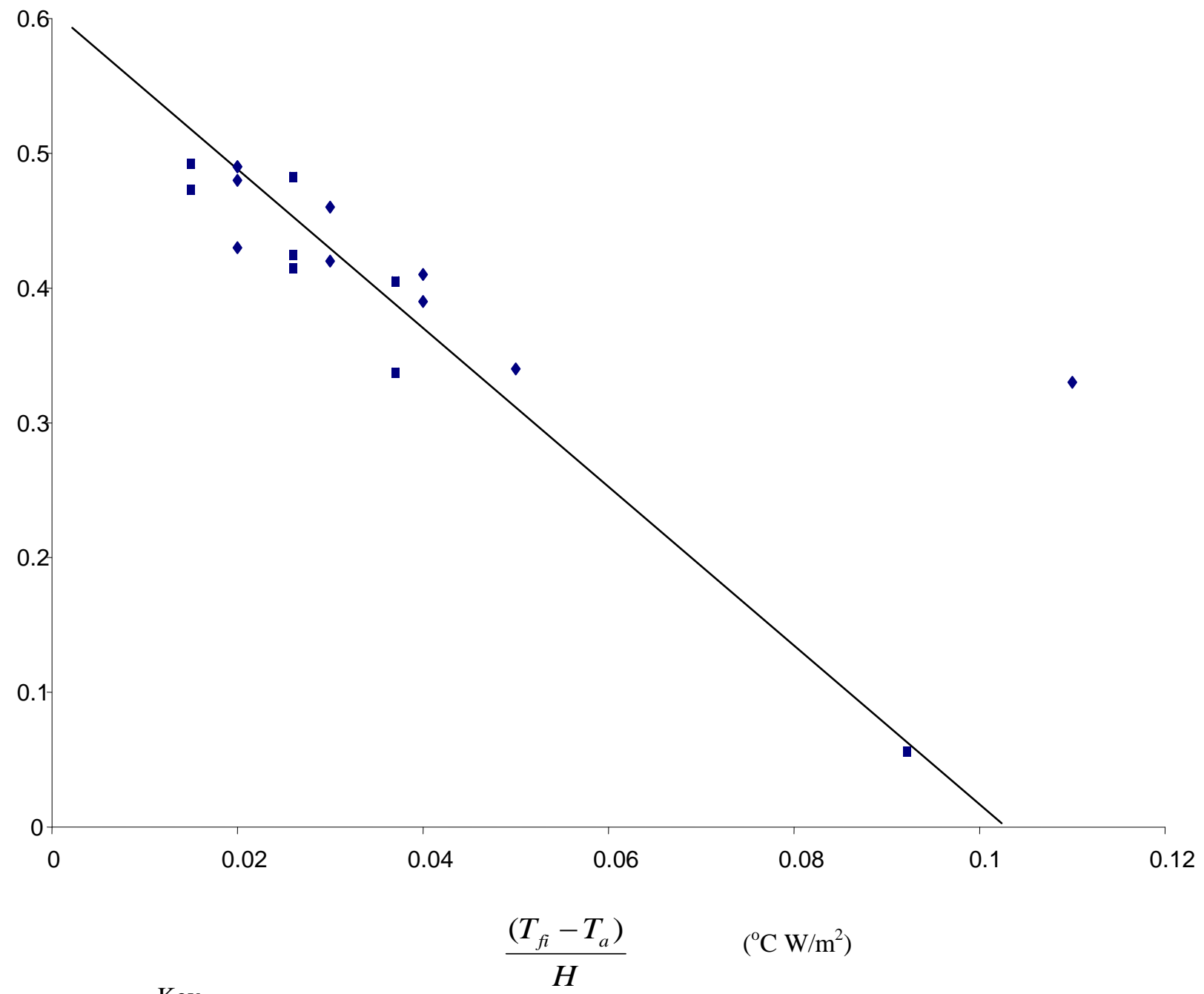

Key

26th October data

$27^{\text {th }}$ October, data 


\subsubsection{Pump Performance Test (Experimental)}

The collection system was filled with $3 \mathrm{~kg}$ of $\mathrm{n}$-pentane liquid. Thereafter it was exposed to the sun at 08.00 hours. Discharge or pump head of $2 \mathrm{~m}$ was

If 2 litres $=0.002 \mathrm{~m}^{3}$

$\therefore$ volmetricflow $(Q)=\frac{0.002}{1 \times 60}$

$=0.000333 \mathrm{~m}^{3} / \mathrm{S}$

From equation 3.35 ,

Hydraulic power can be calculated as

$$
\begin{aligned}
& \rho=\ell g H Q \\
& =1000 \times 9.81 \times 2 \times 0.0000333 \\
& =0.454
\end{aligned}
$$

The overall collector efficiency $(\eta)$ of the pump is given by used for the pump to lift water from a surface water source of not more than $\mathrm{m}$ depth.

It was observed that the pump could lift only 2 litres of water instead of the theoretical 3 litres per cycle and this was achieved at minimum pressure greater than the calculated theoretical pressure. And also it took one minute to pump 2 litres of water.

$\eta=\frac{\text { hydraulicpower }}{\text { solarinsulationXareaofcollector }}$

$$
=\frac{4.54}{956.58 \times 0.96}
$$

$$
=\frac{4.54}{918.32}
$$

$$
=0.53
$$

Table 3. Comparison of the theoretical and experimental results of the pump performance.

\begin{tabular}{|l|l|l|l|l|}
\hline Test & $\begin{array}{l}\text { Pump } \\
\text { Head }(\mathbf{m})\end{array}$ & $\begin{array}{l}\text { Minimum } \\
\text { pressure } \\
\text { pr/Kpal }\end{array}$ & $\begin{array}{l}\text { Volumetric } \\
\text { flow rate (Q) } \\
\mathbf{m}^{\mathbf{3} / \mathbf{s}}\end{array}$ & $\begin{array}{l}\text { Overall } \\
\text { efficiency }(\%)\end{array}$ \\
\hline $\begin{array}{l}\text { Theoretical } \\
\text { experimental }\end{array}$ & 2 & 118 & 5.16 & 0.56 \\
\hline
\end{tabular}

\section{Discussion of Results}

\section{Collector Performance Analysis}

The analyses of the results of the tests are here discussed. $26^{\text {th }}$ October was a sunny day and the sky was clear. A look at table 2 showed that the ambient temperature rose from $31^{\circ} \mathrm{C}$ AT 9.00hours to 38 at 15.00hours and dropped gradually to $33^{\circ} \mathrm{C}$ at 18.00 hours. The insolation rose from $285.61 \mathrm{w} / \mathrm{m}^{2}$ at 9.00 hours to $0.49 \%$ at 11.00 hours and dropped to $0.33 \%$ at 18.00 hours. The daily efficiency was determined to be $0.43 \%$

The table 3 shows the result obtained on $27^{\text {th }}$ October. It was cloudy in the morning and the sky later became clear. The ambient temperature rose from 30 at 9.00 hours to $37^{\circ} \mathrm{C}$ at 15.00 hours on dropped to $32{ }^{\circ} \mathrm{C}$ at 18.00hours. The insolation rose from $286.73 \mathrm{~W} / \mathrm{m}^{2}$ at 9.00hours to $873.02^{\circ} \mathrm{C}$ at 15.00 hours and dropped to $292.63 \mathrm{~W} / \mathrm{m}^{2}$ at 18.00 hours.

A look at figures 1 and 2 show that the collector hourly efficiency increases with decrease in coefficient of performance. The

uncontrolled variables of wind and ambient temperature must have caused a considerable variation in the data.

Generally, in the tests undertaken the largest fraction of useful heat gain by the collector was delivered during periods of high radiation corresponding to when highest temperature were recorded. Mean while, the total solar radiation from collector surface is greatest when it faces the sun directly and decreases at sunrise and sunset periods. The efficiency varies as solar irradiation varies. There are some periods when the efficiencies are so low the reason can be attributed to the followings.

i. The possible errors arising from the values and various formulae used in the computations may effect the calculated overall performance of the solar collector.

ii. The transient operation of the collector as regards the heating to the collector from low to final high temperature experienced $\mathrm{n}$ the morning and afternoon periods.

\section{Pump Performance Analysis}

Experiment was performed and the theoretical and experimental data were compared as shown in table 3. In experiment, the pump required a higher minimum pressure and the pumping process was not instantaneous. And likewise considerable difference exists between the observed and the predicted volumetric flow rates. The theoretical minimum pressure required to pump water is $118 \mathrm{kpal}$ while the experimental value is $87 \mathrm{kpal}$. Theoretical volumetric flow rate is $0.000263 \mathrm{~m}^{3} / \mathrm{s}$ and the experimental flow rate is 0.000033 . Overall efficiency of 
the pump theoretically is 0.56 and that experimental efficiency is 0.53

\section{CONCLUSION AND RECOMMENDATION FOR FURTHER WORK}

\section{Conclusions}

The development of this prototype of solar water pump with flat plate collectors, demonstrates the appropriate technology that can be employed in rural areas where power, skilled technicians and finance are lacking.

This project shows that solar water pumping by means of thermodynamics process, employing a solar thermal system is technically possible and economically competitive with alternative source of energy. The pump uses the energy that is free, renewable and non-polluting. It can be produced using local materials and does not involve complex constructional techniques. Semi-skilled worker under minimum supervision can easily do the fabrication.

Experiment showed that the experimental efficiency of the pump is $0.56 \%$ which is quite low for solar system s employing the flat plate collectors which normally have efficiencies of less than $1 \%$. But it does not in any way suggest that the system or the collector is not functionally sound, as the collector was heated up to 53\% Thus, the low efficiency may be connected with the technical problems experienced during testing and some experimental constraints.

The current cost of the solar water pump is N51, 930:50 excluding labour cost and transportation. It involves the capital cost of purchase and doe not involve recurrent cost of running and maintenance like its conventional type.

\section{Recommendations for further work}

For further work on solar water pump, the following recommendations will increase the cost of production and also the mass production of the pump will reduce the production cost, but enhance greater efficiency

1. More than one flat plate collector should be arranged in series with a view to getting a much higher temperature.

2. The performance of the glass cover can be improved by depositing a transparent coating on its inner surface which allows nearly all the incident solar radiation to be transmitted.

3. The collector box should be made of aluminum sheets because of tiks light weight and corrosion preventing property.

4. The use of a combination of an outer glass cover with inner cheaper transparent to plastic film can be advantageous as the plastic has a higher transmittance than glass.

5. Aluminum absorber plate should be used instead of galvanized absorber plate because of its higher thermal conductivity.

6. The working fluid should be charged into the system in the night when the ambient temperature is low to reduce risk of loss due to evaporation.

7. A lower boiling point organic compoundmethane, should be employed in place of pentane to educe they vaporization time of the working fluid. 


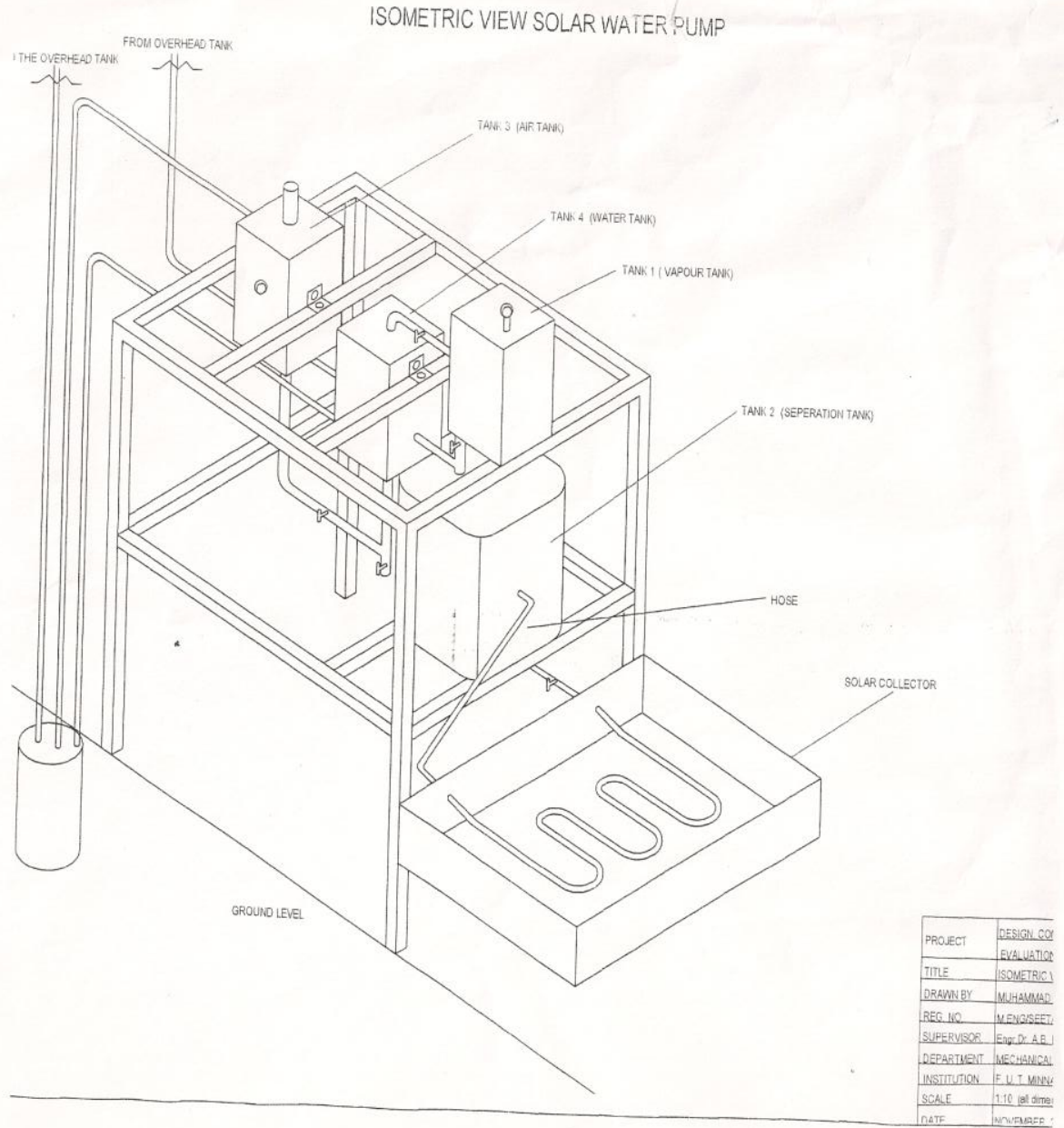

\section{REFERENCES}

1. BAMIRO, O.A., NURUDEEN, A. AND

2. AKURU, I.O. (1982).Introductory technology for school and colleges, new edition, Evans brother (Nigeria Publishers) limited Pp213.(Ibadan).

3. CHANDRA, M. AND OGUNTUASE, O.

4. (1996). A natural convention solar water pump for an application in Nigerian buildings. Nigerian journal of solar energy, John A. Volume 5, Pp 154-157 (Lagos)

5. DUFFIE, J.A. AND BECKNAN, W.A

6. (1980) Solar Engineering of Thermal Processes. John Wiley and sons Inc, U.S.A pp 121 -180.

7. EZEILO, C. (1994). Sun table for Nigeria

8. Latitude, Nigerian Journal of Solar Energy, Volume 4, pp3-9. Zaria

9. OLUSOJI, O. (1983). The design

10. construction and evaluation of a solar water heater. Nigerian journal of solar energy, volume 3 , pp 18-25. Ibadan 